\title{
VALORES Y RACIONALIDAD: \\ Hilary Putnam y el legado \\ de la filosofía norteamericana.
}

Ramón del Castillo.

Departamento de Filosofía. UNED.

Mi intención en este trabajo es mostrar algunas relaciones entre la obra de Hilary Putnam y el legado de la tradición filosófica norteamericana más importante: la pragmatista. Aunque el término 'pragmatismo' se ha ido asociando en los últimos años con la polémica obra de Richard Rorty, es importante recordar que, desde que en los años sesenta Putnam presentara su "realismo interno", las referencias a Peirce, James y Dewey han sido cada vez más frecuentes y explícitas en su obra. En Razón, verdad e historia la figura de Peirce aparecía al hilo de las críticas que Putnam dirigía al primer operacionalismo. Putnam insistió en aquellos aspectos de la filosofía de la ciencia de Peirce que podían ser compatibles con las doctrinas de Quine que tanto han influido en su propia concepción de la ciencia ${ }^{1}$. Tras la publicación de esta popular obra a principio de los años ochenta, las opiniones de Putnam sobre la epistemología pragmatista se han precisado mucho más, sobre todo con el conjunto de pequeños trabajos dedicados a la filosofía americana que incluyó en 1990 la tercera parte de Realism With a Human Face. Lo que sin duda ha interesado más a Putnam de los pragmatistas es que, a diferencia de Mill, Reichenbach o Carnap, ninguno de ellos concibió la epistemología "como una empresa

Putnam, H., Reason, Truth and History, Cambridge, Cambridge University Press, 1981. Traducción castellana: Razón, oerdad e historia, Madrid, Tecnos, 1988, pp. $40-42$.

Éndoxa: Series Filosóficas, $n^{\circ} 4,1994$, UNED, Madrid:

Ramón del Castillo: Valores y racionalidad: Hilary Putnam y el legado de la filosofía norteamericana.

pp. 99-128. 
cuyo fin fuera reducir la racionalidad a un conjunto de normas"2. En especial, (i) la insistencia pragmatista en que no es posible distinguir entre métodos y contenido de la racionalidad científica y práctica; (ii) que los criterios que relacionan la teoría con la experiencia son ellos mismos algo que evoluciona en el curso de la experiencia; y (iii), por encima de todo, que la coherencia, la simplicidad, la eficacia instrumental y otras propiedades de las teorias son ellas mismas valores sin los cuales "no tendríamos mundo ni hechos"; estos valores cognitivos son, como para los pragmatistas, "simplemente una parte de nuestra concepción holística del crecimiento humano".3.

En realidad, la relación entre la epistemología pragmatista y la de Putnam es un tema más complicado de lo que pudiera parecer. A este respecto, no se deberían pasar por alto, por ejemplo, comentarios como el que Putnam hizo en "Why There Isn't a Ready World". Allí decía que su 'realismo interno' "sería una especie de pragmatismo, aunque la palabra 'pragmatismo'se ha entendido siempre tan mal que se llega a perder la esperanza de rescatar el término"'. Más recientemente, en la serie de conferencias The Many Faces of Realism, Putnam también ha señalado que al realismo interno, --el programa consistente en "preservar el realismo del sentido común $y$, al mismo tiempo, evitar las antinomias del realismo metafísico"--, podría haberlo llamado "realismo pragmático". . En efecto, el concepto pragmatista de verdad y el concepto de Putnam de verdad como idealización de la aceptabilidad racional comparten semejanzas importantes, pero también diferencias que el propio Putnam se ha preocupado de

2 H. Putnam, "William James's Ideas" Realism with a Human Face. Cambridge, Harvard University Press, 1990, p. 219.

3 "Beyond the Fact/Value Dichotomy", Realism with a Human Face, p. 139.

4 H. Putnam, Realism and Reason. Philosophical Papers, Vol. III, Cambridge, Cambridge University Press 1983, p. 225. 17.

5 H. Putnam, The Many Faces of Realism, La Salle, Illionis, Open Court, 1987, p. 
precisar. Este problema ha merecido en los últimos años una gran atención, pero aquí no me ocuparé directamente de él'.

I

El tema que discutiré aquí es la relación, más desapercibida, que existe entre el modelo de la racionalidad práctica de Putnam y el pragmatista, en concreto el de John Dewey. El punto de partida de esta discusión podrían ser las interesantes observaciones que ha hecho Putnam en The Many Faces of Realism, en Renewing Philosophy y, sobre todo, en un artículo escrito en colaboración con Ruth Anna Putnam: "Epistemology as Hypothesis", dedicado tanto a la filosofía de la ciencia de Dewey como a su teoría del valor? En efecto, en estos trabajos Putnam parece conectar con Dewey su propia tesis de que la noción de racionalidad es, en el fondo, una parte de nuestra idea de lo bueno. $O$, dicho de otra manera: "desacreditada la antigua concepción realista de la verdad como correspondencia y la idea positivista de la justificación como algo fijado por criterios públicos, nos vemos obligados a admitir que nuestra búsqueda de mejores concepciones de la racionalidad es una actividad intencional que, como toda actividad que se sobrepone a las meras inclinaciones u obsesiones, está guiada por

6 Sugerentes comparaciones entre el ralismo interno de Putnam y el realismo de Peirce se pueden encontrar en Skagestad, P., The Road of Inquiry. Charles Peirce's Pragmatic Realism. New York, Columbia University Press, 1981. Y del mismo autor: "American Pragmatism", Contemporary Philosophy. A New Suroey, IV, The Hague, Martinus Nijhoff, 1983, pp. 363-386. He analizado este punto en mi artículo "Realismo, verdad y aceptabilidad racional: de Peirce a Putnam" (inédito). Las opiniones más interesantes de Putnam sobre Peirce se encuentran en el prólogo a Realism With a Human Face y, sobre todo, en la introducción y el comentario que ha hecho de las conferencias que Peirce dio en Cambridge en 1898: Peirce, Ch. S., Reasoning and the Logic of Things, Ketner, K., (ed.), Cambridge, Harvard University Press, 1992, pp. 55-104. Es importante observar que los argumentos del pragmatismo que Putnam ve conciliables con el holismo de Quine fueron reconocidos por el propio Quine en su artículo: "The Pragmatist's Place in Empiricism", Pragmatism. Its Sources and Prospects, Mulvaney, R. \& Zeltner, P., (eds.), University of South Carolina Press., 1981, pp. 23-39.

7 Transactions of the Charles S. Peirce Society, XXVI, 1990, pp. 407-434. 
nuestra idea del bien"8. El núcleo de esta afirmación responde a la convicción de que ha habido un error en la concepción usual de los juicios de valor. Putnam ha denunciado repetidamente que dicha concepción ha estado demasiado influida por la idea positivista de que los juicios de valor no tienen contenido cognitivo sino, como mucho, emotivo. Sin embargo, como señala Putnam en "Objectivity and the Science/Ethics Distinction", el enmarañamiento (entanglement) de hecho y valor "fue un tema costante en los escritos de Dewey. Pero ese aspecto del pragmatismo fue olvidado en la filosofía angloamericana tras la muerte de Dewey, a pesar de los valientes esfuerzos de Morton White por mantenerlo vivo, y fue quizás Iris Murdoch quien retomó el tema aunque de una forma muy diferente ${ }^{t 9}$.

8 Realism with a Human Face, p. 139.

9 Realism with a Human Face, p. 166. Las alusiones de Putnam a Murdoch son frecuentes. $Y$, en efecto, a pesar de que las ideas de Murdoch difieren por carácter e intención de las de Dewey, hay dos puntos que merecería la pena destacar. Según Putnam, en The Sozereignty of "Good", Murdoch ha llamado la atención sobre el hecho de que nuestros lenguajes tienen dos clases muy diferentes de términos éticos: abstractos (como 'bien' y 'correcto') y descriptivos (como 'cruel', 'impertinen-

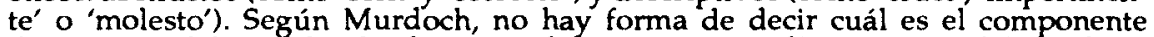
descriptivo del significado de una palabra como 'cruel' sin usar palabras de la misma clase. Para que estas palabras se usen asi, deben estar unidas a intereses evaluativos con los que los agentes han de ser capaces de decidir imaginativamente si se ha de aplicar la palabra a nuevos casos o circunstancias. Para Putnam, el intento de las éticas no cognitivistas (como el positivismo) de separar en esas palabras un componente descriptivo y otro prescriptivo se basó, precisamente, en la imposibilidad de distinguir cuál es el significado descriptivo de 'cruel' sin usar esa palabra o un sinónimo.

La segunda idea que interesa a Putnam de Murdoch es que, cuando nos enfrentamos a situaciones que requieren evaluaciones éticas, necesitamos descripciones de este estilo, aunque no son descripiones en el sentido del positivismo. Por ejemplo, aun cuando cada uno de los siguientes enunciados: " $X$ es poco amable", "X sólo piensa en sí mismo", "X haría cualquier cosa por dinero", puede ser una descripción verdadera en el sentido más positivista (" $X$ haría cualquier cosa por dinero" no contiene ningún término de valor), si uno establece la conjunción de los tres enunciados, no es necesario añadir que $X$ no es muy buena persona. Cuando se han concebido hechos y valores como cosas independientes, se ha pensado que los hechos se podían describir en una jerga fisicalísta, y que los valores necesitan términos de valor más abstractos. Pero es difícil, según Putnam, seguir manteniendo la distinción entre hechos y valores cuando los primeros son del tipo de 'poco amable', 'piensa sólo en si mismo' o 'haría cualquier cosa por dinero' (Razon, verdad e historia, pp. 142-143; Realism with a Human Face, pp. 166-167). 
Ya en Razón, verdad e historia Putnam analizó en detalle las relaciones entre racionalidad y valor y sugirió que las discusiones modernas y contemporáneas sobre este problema han resultado para muchos poco concluyentes, quizá porque se ha dado cierta prioridad a la racionalidad sobre el valor. La pregunta que ha dominado --dice Putnam-- es si hay algún sentido en el que pueda llamarse "irracional" a la elección o preferencia por un fin malo, como si la bondad estuviera sometida a juicio y la racionalidad fuera el juez. Según Putnam, los filósofos antiguos y medievales no encontraban extraño decir que si $x$ es una vida mejor que $y$, entonces, este hecho es una razón para elegir $x$ frente a $y$. La racionalidad, para estas tradiciones, era una facultad de escoger fines sobre la base de su bondad (en oposición a las pasiones, que intentan dictar normas sobre la base de los apetitos o "inclinaciones"), de forma que es racional elegir lo bueno. Esto respalda, a su vez, la pretensión de que la bondad y la maldad son objetivas. Evidentemente --dice Putnam-- no podemos retroceder hacia la cosmovisión antigua o medieval, como podrían desear los conservadores, pero tampoco habría por qué aceptar que la única alternativa que nos queda es el modelo moderno de racionalidad, donde la bondad de un fin no hace particularmente irracional el que no se escoja, o que se escoja un fin manifiestamente malo, respaldando así la pretensión de que la bondad y la maldad no son objetivas. Se necesita invertir los términos de la comparación entre racionalidad y bondad y desplazar preguntas como ¿cúan racional es la bondad? hacia otras preguntas como ¿qué valor tiene la racionalidad? o ¿por qué es bueno ser racional? Sólo así, decía Putnam, podríamos entender muchos de los errores que ha padecido la comprensión moderna de los juicios de valor: "La línea popular de pensamiento hoy día no deja lugar para la idea tradicional de la razón como una facultad que nos dicta fines, y no sólo medios para fines dictados por el instinto y modificados por condicionamientos. El dictum de Hume de que la razón es y debe ser esclava de las pasiones, expresa con exactitud esta idea moderna: la razón se identifica con la razón instrumental. Pero si 
la razón no puede dictar fines, entonces no hay razón por la que yo deba oponerme a mis pasiones, excepto la inadecuada razón de otra pasión. No puede haber una respuesta racional a: ¿por qué debería hacer lo que debo? Y una respuesta irracional que se admite o reconoce como irracional o arracional no es buena"10.

Nadie duda de que el conocimiento científico tenga un enorme valor práctico, pero aun cuando se valorase ese conocimiento únicamente por sus aplicaciones, porque nos permite descubrir conexiones fiables entre medios y fines, ¿por qué ha de valorarse la racionalidad por sus aplicaciones? Claro que es de gran valor disponer de instrumentos que nos ayuden a seleccionar medios eficaces para la obtención de fines, dice Putnam, pero también es valioso saber qué fines hemos de escoger. No es sorprendente, por tanto, que se crea que la verdad de los juicios de valor no puede ser racionalmente demostrada si la verificación racional ha estado limitada al establecimiento de conexiones medios-fines. Si reducimos no sólo la ciencia, sino cualquier discurso cognitivamente significativo, a un método para establecer una cantidad de hechos de la forma: si realiza tales y tales acciones obtendrá tales y tales resultados, quizá encontraremos dificultades para dar significado a la afirmación de que llamar a algo "bueno" es llevar a cabo una predicción de la forma: si realiza tales y tales acciones, obtendrá tales y tales resultados. Podemos, por tanto, afirmar que los enunciados respecto a la bondad o la maldad de algo no tienen significado cognitivo sino, como dijeron los empiristas lógicos, "significado emotivo"11.

10 H. Putnam, "The Place of Facts in a World of Values", Realism with a Human Face, p. 150.

11 La idea de que la racionalidad consiste en métodos que dan por resultado el descubrimiento y el establecimiento público de conexiones entre medios y fines se retrotrae, según Putnam, al empirismo clásico, se desarrolla con Mill y llega hasta el empirismo lógico del siglo XX. El empirismo lógico, dice Putnam, intentaba, en el fondo, disolver el conflicto entre el interés de una teoría por sus consecuencias instrumentales y el interés por el conocimiento en sí mismo. El conflicto podía resultar artificial si se admite que hay una diferencia entre esos tipos de intereses, pero también si se admite que todo conocimiento que merezca ese nombre se habría mostrado como un conocimiento de una gran cantidad de hechos de la forma: si realiza tales y tales acciones, obtendrá tales y tales resultados. Cualquiera que sea el 
Putnam aborda en detalle los problemas que ha tenido esta concepción estrecha de la racionalidad como conocimiento de conexiones medios--fines, pero lo que me interesa de esto es su relación con el interés de Putnam por la teoría del valor de Dewey. En principio, es comprensible que Putnam interprete el modelo pragmatista como una alternativa relevante, dado que Dewey flexibilizó la noción de la racionalidad como descubrimiento de conexiones medios-fines, insistiendo, por ejemplo, en la indeterminación de las correlaciones entre actos, considerados uno a uno, y sus consecuencias, así como en la influencia que ejercen hábitos vagos sobre el establecimiento de esas conexiones. Es cierto que para Dewey la racionalidad atañe principalmente a la conexión medios-fines, pero él no concibe ese tipo de conocimiento como la aplicación de reglas o de un método formal. Esas conexiones presuponen valores, y éstos se definen en el establecimiento experimental de conexiones, de forma que ni los juicios de valor carecen de contenido cognitivo ni la racionalidad se reduce a un cálculo formal.

motivo por el que nos interesen, todos los hechos son, en última instancia, instrumentales. Sólo llamamos prácticos a nuestros intereses cuando estamos interesados en la conexión medios-fines, porque esperamos explotarla de cara a la obtención de algún fin; y los llamamos "teóricos" cuando nos interesa conocer la conexión medios-fines por pura curiosidad.

Hasta cierto punto, los pragmatistas sostuvieron antes que los empiristas lógicos la idea de que todo conocimiento significativo se basa en predicciones de la forma: Si realizas tales y tales acciones, obtendrás tales y tales resultados. En Esseys on Experimental Logic, afirma que el objeto del conocimiento "no es algo con lo que empieza el pensamiento sino algo en lo que termina, algo que los procesos de investigación y prueba que constituyen el pensamiento, producen por sí mismos. Así, el objeto de conocimiento es práctico en el sentido de que depende de un tipo específico de práctica para existir, para existir como objeto de conocimiento. Determinar lo práctico que pueda ser en cualquier otro sentido, es un problema completamente diferente. (...) No conocemos el origen, la naturaleza y el remedio de la malaria hasta que no logramos tanto producirla como eliminarla: el valor de la producción o eliminación depende de la índole de la malaria en relación con otras cosas. Lo mismo ocurre con el conocimiento matemático, o con el político o al artístico. Su objetos respectivos no se conocen hasta que no se elaboran en el curso del proceso del pensar experimental. Su utilidad, una vez elaborada, será desde infinita hasta nula, lo que la experiencia subsiguiente determine al respecto" (Essays on Experimental Logic. Chicago, University of Chicago Press, 1916, pp. 330334. El subrayado es mío). 
Para entender esto, veamos con más detalle cómo analiza Putnam los modelos utilitaristas de racionalidad. Según estos modelos, la elección de fines y metas no es ni racional ni irracional, mientras que la elección de medios es racional en la medida en que es eficaz; la preferencia de un agente racional por $x$ frente a $y$ no es ni racional ni irracional, pero la de elegir $x$ y no $y$ en una ocasión determinada sería racional dado su "orden de preferencia". Según Putnam, en estos modelos el valor, de ser algo, es producto de las preferencias consideradas de forma independiente. No hay medios para ponderar el valor relativo de $x$ frente a $y$, dejando a un lado el hecho de que el agente prefiere una cosa o la otra. Es decir, no se afirma que prefiramos $x$ a $y$, porque $x$ tiene más valor que $y$, sino más bien lo contrario: $x$ tiene mayor valor que $y$ porque se prefiere $^{12}$. La preferencia de A por el helado de vainilla frente al de chocolate no es ni racional ni irracional, pero elegir vainilla y no chocolate seria racional para $A$ dado su orden de preferencias.

Esta concepción --sigue diciendo Putnam-- pierde gran parte de su poder persuasivo cuando comprendemos que descansa sobre una teoría de la acción excesivamente simplificada. En los esquemas utilitaristas los fines, las metas y las preferencias se tratan como parámetros individuales fijos o bien como parámetros individuales que, si no son fijos, sólo cambian como resultado de factores que no tienen carácter racional; esto es, como resultado de propiedades de la acción de las que el modelo teórico, por definición, no puede dar cuenta. Los juicios de valor, comenta Putnam, a menudo forman grupos, y estos grupos revelan con frecuencia rasgos más o menos permanentes del carácter. Sin embargo, "la independencia de 'prefiero el helado de vainilla al de chocolate' respecto a cualquier grupo de ese tipo, es lo que convierte a ese juicio en algo subjetivo para el modelo utilitarista, junto con la ausencia de importancia intrínseca en la misma elección"13. Cuando Putnam afirma que en este modelo el

\footnotetext{
12 Véase Razón, verdad e historia, cap. 7.

13 Ibid., p. 156. Véase también The Many Faces of Realism, p. 56 y ss..
} 
aprendizaje se representa como un proceso consistente en aprender a estimar mejor las consecuencias probables de las acciones, y a alcanzar los fines de una manera más eficiente, pero no como un proceso de adquisición de nuevos fines ${ }^{14}$, está utilizando un argumento de Dewey.

Putnam da varios pasos hasta enunciarlo con un léxico deweyano. Recuerda que para el modelo utilitarista el abandono de un fin por parte de un agente no se debe al resultado de una crítica racional. Para el utilitarismo, ese abandono se explica como resultado de una mala estimación de las consecuencias que tiene perseguir ese fin en relación con otros fines. Pero, en realidad, Putnam considera que el abandono de fines sería un problema que trasciende esa consideración y que da pie a la pregunta: ¿en qué consiste efectivamente, como parte de la experiencia, alcanzar ese fin? Muchos seres humanos persiguen fines cuya obtención no les satisfaría ni en tanta medida ni por tanto tiempo como ellos piensan. Se podría admitir como parte de las decisiones racionales aquellas que dependen de estimaciones de lo que Putnam llama atractivo existencial de los fines. Los agentes pueden pasar por alto fines que podrian perseguir si fueran capaces de desarrollar más conocimiento e incluso si fueran capaces de desarrollar metáforas para imaginar en qué consistiría la obtención de esos fines, "máxime --conclye Putnam-- si esas metas consisten en rasgos del carácter a largo plazo (...) y no en una cosa o en un acontecimiento"15.

Supongo que Dewey tenía en mente una idea parecida cuando decía que los "utilitaristas buscan una ecuación entre acto y consecuencias y pasan por alto que cualquier correlación entre un acto y su consecuencia presupone la tendencia (indeterminada para cualquier estado concreto) de ese acto y el tipo de consecuen-

\footnotetext{
14 Razón, verdad e historia, p. 170.

15 Ibid., p. 171.
} 
cias inesperadas que puede llegar a producir en su desarrollo"16. En la racionalidad que Dewey llama "ordinaria", los fines son términos de una deliberación tentativa que no es contradictoria con la observación de las consecuencias que podrían transformar ese fin y crear un nuevo fin o plan de acción. En estos casos, las alternativas no se consideran iguales, sino que se incita a un tipo de reflexión en la que lo apremiante es descubrir una forma de actividad misma. En este caso --decía Dewey-- la deliberación no se puede reducir a una consideración de costes en términos utilitaristas, sino que es "un intento de descubrir el conflicto en todo su alcance y significado"17. Existe una diferencia radical entre la deliberación cuyo único objeto es saber cómo aplicar los medios más eficaces y "aquella en la que la decisión primordial se refiere a la clase de actividad que vaya a emprenderse"18. Dewey lo explica con el siguiente ejemplo: si $\mathrm{A}$ ha tomado la decisión de pasear, hay un sentido de "deliberar" según el cual sólo delibera acerca de qué camino tomar en su paseo. La deliberación en ese caso tiene por objeto comparar las ventajas de ir a una $u$ otra parte. Pero supongamos por un momento que la disyuntiva de $\mathrm{A}$ no está en qué camino tomar, sino "entre caminar o permanecer con un amigo al que el continuo encierro ha vuelto irritable y poco interesante como compañero; la teoría utilitarista sostiene que en el último caso las dos alternativas siguen siendo de la misma clase. (...) Este supuesto es impugnado por los hechos: la agudeza de las situaciones que incitan a la reflexión estriba en el hecho de que realmente desconocemos la finalidad de las tendencias que presionan por actuar; tenemos que investigar y experimentar, y la deliberación es una labor de descubrimiento. (...) Para abreviar, lo que verdaderamente está en juego en cualquier deliberación seria no es una diferencia en cantidad, sino la clase de persona en la

\footnotetext{
16 John Dewey, Naturaleza humana y conducta. México, F.C.E. pp. 56-57. Véanse también pp. 186-195.

17 Ibid. p. 201.

18

Ibidem.
} 
que se va uno a convertir, qué especie de ser está en formación y qué clase de mundo está haciendo. (...) La deliberación acerca de si se va a ser un comerciante o un maestro de escuela, un médico o un político, no es una elección de cantidades, sino exactamente lo que parece ser, una elección de carreras incompatibles entre sí, dentro de cada una de las cuales hay que efectuar inclusiones y exclusiones definitivas" ${ }^{\prime \prime 19}$.

Es sorprendente la similitud entre estos ejemplos de Dewey y los ataques de Putnam contra el utilitarismo. Como dice Putnam en The Many Faces of Realism, unas versiones del utilitarismo basarían el concepto de decisión racional en la noción de maximización de la felicidad; insiste en que debemos hacer feliz a la gente, pero, dice Putnam, debemos hacer eso sin dañar la libertad de la gente para decidir por sí misma qué es la felicidad. Lo que pasa desapercibido en el utilitarismo es la forma en la que también elude el valor de la elección libre, sin comprometerse en su representación de la realidad con ninguna fuente que defienda ese valor que pudiera proceder de una modesta imagen del carácter humano. El utilitarismo, dice, es un intento de que ideas serias que tienen complejas raíces en nuestra cultura parezcan simples ${ }^{20}$. Es cierto que, cuando Putnam dice todo, lo hace en el contexto de un comentario sobre la ética kantiana, pero el móvil de su crítica al utilitarismo presenta un aire aristotélico, máxime si, como admite, se apoya en el naturalismo de Dewey.

Cuando Putnam critica el utilitarismo, también insiste en muchos casos donde los errores al elegir fines (la racionalidad de la deliberación) se deben, así mismo, a que el problema no radica tanto en hallar medios para el fin como encontrar un patrón global de actividad que constituya una especificación aceptable de ese fin. Putnam utiliza un ejemplo de Bernard Williams: Imaginemos que el fin es "pasar un buen rato esta tarde". El problema no es tanto encontrar medios para satisfacer ese fin como encontrar una

19 Ibid. pp. 200-201.

20 The Many Faces of Realism, pp. 58-60. 
especificación aceptable de él, por ejemplo, "permanecer en casa leyendo" o "visitar a unos amigos". El ejemplo es oportuno y, en definitiva, recuerda un problema que ya se planteara Aristóteles al preguntarse: ¿En qué consiste la eudaimonia?

Traigo a colación a Aristóteles por varias razones: primero, porque el propio Putnam señala que el ejemplo de Bernard Williams reaviva afirmaciones que se retrotraen a Aristóteles ${ }^{21} ; y$, segundo, porque Dewey tuvo en cuenta el modelo aristotélico de la proairesis cuando describió los casos de deliberación en los que las acciones se llevan adelante no $r$ rque sean un medio eficaz para producir un objeto, sino porque hacerlas es realizar ese fin. No es extraño que Dewey cite en varias ocasiones ${ }^{22}$, aunque de forma poco clara, las observaciones de Aristóteles en el tercer libro de la Ética a Nicómaco para apoyar su propio punto de vista sobre la naturaleza de la deliberación práctica. Si el punto que Dewey quería ilustrar era que en muchos casos la deliberación práctica no es una investigación sobre medios (pasos por los que producir un resultado o un objeto), sino una investigación sobre qué hay que hacer si se quiere realizar una acción de cierta clase, puede que hubiera encontrado apoyo a esa idea en ejemplos de Aristóteles donde un agente "delibera" en el sentido de que concluye que debe hacer ciertas acciones porque son acciones de cierta clase, porque actuar de esa manera es lo que se persigue, es el fin. En realidad, los ejemplos de Dewey (y, por extensión, los de Putnam) guardarían un paralelo con la idea aristotélica de que un medio no es siempre un simple instrumento para alcanzar un fin, sino una forma de realizar ese fin. En estos casos, los medios pueden ser acciones y hábitos y no simples cosas, y la relación que guardan

21 Razón, verdad e historia, p. 171.

22 John Dewey, The Middle Works. 1899-1924, vol. VIII, Boydston, J. A., (ed.), Southern Illinois University Press, 1976-83, p. 37. 
esos medios y los fines es "interna": aquéllos constituyen en algún sentido a éstos ${ }^{23}$.

II

Como vemos, los argumentos de Putnam guardan un gran parecido con los de Dewey. Ambos se apoyan en ejemplos que nos retrotraen a la ética naturalista clásica, aunque obviamente ninguno de los dos intenta rehabilitar la concepción premoderna de la naturaleza humana. Les interesan, ante todo, los problemas suscitados por una concepción estrecha de la racionalidad ${ }^{24}$.

23 Dewey expresaba también esta idea cuando decía que lo que caracteriza a los juicios prácticos es que el acto mismo de producir el juicio es un factor determinante del modo como se completara la situación. Lo juzgado en los juicios prácticos no es algo externo al acto de juicio, "la situación es la que es, por obra de la actitud que encuentra expresión en el acto mismo de juzgar (...) el juicio está destinado a juzgar un objeto en cuya determinación, la actitud o disposición misma que conduce al acto de juzgar, es un factor. El fin de estos juicios consiste, por tanto, en construir el acto de juicio, como constituyendo en sí mismo un contenido objetivo complejo $\mathrm{y}$, justamente porque en el objeto examinado y organizado se halla implícito el carácter o la disposición, el propio carácter se ve determinado por el juicio. En estos juicios, deben ser determinadas las propias condiciones de la actividad de juicio. Se construye como objeto la condición que controla toda la actividad judicativa" (John Dewey, El hombre y sus problemas, Buenos Aires, Paidós, 1952, pp. 202-204). Para una comparación entre Dewey y Aristóteles, véase el capítulo VII (Objectivity, Value and Motivation) de Tiles, J., John Dewey, London, Routledge, 1988. Tiles apoya la comparación en la interpretación que D. Wiggings hizo de Aristóteles en "Delíberation and Practical Reason", en Rorty, A., (ed.), Essays on Aristotle's Ethics, Berkeley, University of California Press, 1980.

24 "Si hoy discrepamos con Aristóteles --comenta Putnam- es porque somos mucho más pluralistas que él. Aristóteles reconocía que diferentes ideas de eudaimonia, diferentes concepciones del [crecimiento] humano, podrian ser adecuadas para diferentes individuos, teniendo en cuenta sus diferentes constituciones. Pero parecía pensar que, idealmente, habría algún tipo de constitución que todo deberíamos tener, que en un mundo ideal (olvidando las cuestiones mundanas de quién cultivaría las cosechas y quién cocería el pan) todo el mundo sería filósofo. Nosotros coincidimos con él en que diferentes concepciones del [crecimiento] humano son adecuadas para individuos con diferentes constituciones, pero vamos más lejos al creer que incluso en el mundo ideal habria diferentes constituciones, que la diversidad es parte del ideal. Y observamos algún grado de tensión trágica entre los ideales, esto es, que el cumplimiento de algunos ideales excluye siempre el cumplimiento de otros. [No obstante] creer en un ideal pluralista no es lo mismo que creer que cualquier ideal del [crecimiento] humano es $\tan$ bueno como cualquier otro" (Razón, verdad $\varepsilon$ historia, p. 151). Creo que esta actitud es extremadamente parecida a la que Dewey adoptó hacia la ética naturalista clásica. Véanse a este respecto los comentarios sobre Dewey y Aristóteles en los capítulos IV ("EI 
Volvamos de momento a la relación entre Putnam y Dewey. La influencia del segundo sobre el concepto de racionalidad práctica de Putnam no acaba aquí. En "Rationality in Decision Theory and in Ethics" (1989) y en "Epistemology as Hypothesis" (1990), la crítica a las teorías contemporáneas de la racionalidd siguen inspirándose en un lema deweyano que Putnam enuncia así: "Estamos atrapados por una distinción culturalmente aceptada entre ciencia y ética; pero también por otra: la distinción entre valores absolutos e instrumentales. En efecto, la distinción entre valorar e instrumentar ${ }^{\prime 25}$ A lo largo de estos trabajos, como en Razón, verdad e historia, se insiste en que lo que se ha concebido como "instrumentación" es una noción tan problemática como la de "valorar". Putnam, en esta ocasión, opone de una forma muy detallada la concepción de Dewey a la que expuso su maestro Hans Reichenbach a finales de los años treinta y a la teoría formal de la decisión de von Neumann.

Según Reichenbach, los fines últimos de un individuo no se pueden evaluar racionalmente. No podemos negar que valoramos ciertas cosas o que perseguimos otras (alimentación, cobijo, belleza, amistad, conocimiento). Pero en un mundo reichenbachiano --dicen Hilary y Rut Putnam-- no se puede decir nada sobre esos esos fines y "sobre todo, no se puede decir nada más sobre instanciaciones de ellos más o menos específicas". Valorarlos no es, pues, ni racional ni irracional, y sólo podemos investigar sobre los medios para su satisfacción. Después de esto, los Putnam imaginan cómo respondería Dewey a Reichenbach. En primer lugar, diría que es erróneo hablar de la existencia de fines "genéricos" como los que se han enumerado arriba. Al buscar algo específico bajo cada uno de esos términos, no vemos con claridad que esos bienes, en la

\footnotetext{
pragmatismo y la construcción del valor") y VII ("El optimismo pragmatista de Dewey: entre el constructivismo social y la racionalidad de las costumbres"), en del Castillo, R., La práctica y los límites de la interpretación. El pragmatismo de Peirce, Dewey y Wittgenstein, Madrid, Universidad Complutense, 1993.

25 "Rationality in Decision Theory and in Ethics", Biderman, S., \& Scharfstein, B., (eds.): Rationality in Question, E. J. Brill, 1989.
} 
medida en que los perseguimos, funcionan como medios y pueden ser evaluados. Para Dewey, los fines no son ni entidades platónicas ni deseos arbitrarios de los individuos, sino guias para la acción y, en la medida en que tienen esa capacidad para modificar y desarrollar la conducta, "ellos mismos son medios para solventar un problema y la racionalidad es competente para pronunciar juicios sobre ellos". Al formular fines que guían la acción, lo que Dewey denominó "ends-in-view", no es razonable establecer aquellos carentes de conexión con medios disponibles y que no hacen referencia a los obstáculos que surgen en el proceso de la obtención del fin; por eso, los fines-a-la-vista no son términos últimos. Una vez alcanzados, llegan a formar parte de una situación práctica en la que nuevos problemas surgirán. Retrospectivamente, siempre podemos decir que habriamos hecho mejor persiguiendo un fin diferente. "La existencia --dicen los Putnam-de fines genéricos, y no estamos negando su utilidad, conduce a confusión, porque tendemos a pensar que esos fines son absolutamente buenos. Pero describir una meta más específica como un caso de alguno de esos términos generales, por ejemplo, como un caso de conocimiento, podría conducirnos equivocadamente a pensar que es permisible perseguirlo. Pero hay conocimientos que no deberíamos perseguir (por ejemplo, cómo torturar). Incluso el conocimiento valioso no puede ser obtenido con cualquier medio (...). La racionalidad de medios-fines nos permite evaluar fines en términos del coste de los medios que requiere su obtención" ${ }^{\prime 26}$.

Esta interpretación de Dewey es muy acertada porque expresa muy bien su insistencia en que "no podemos buscar ni alcanzar la salud, la riqueza, el conocimiento, la justicia o la bondad en términos generales"27, porque la acción es siempre específica y concreta. Para Dewey esto significaba que los juicios referidos a los

\footnotetext{
26 Epistemology as Hipothesys, p. 410.

27 Reconstruction in Philosophy, New York, The New American Library of World Literature, $1950^{3}$, cap. VII. Hay traducción castellana, La reconstrucción de la filosofía, Buenos Aires, Aguilar, 1955, p. 230.
} 
actos que tenemos que realizar tendrán que ser también específicos. En sus propias palabras: "decir que un hombre busca la salud o la justicia, es lo mismo que decir que busca vivir saludable o justamente ${ }^{128}$. Por tanto, el punto sobre el que insisten los Putnam es que, aunque llamemos "bienes" a cosas como el conocimiento o la justicia, éstas no son sino instrumentos para provocar respuestas en situaciones específicas ${ }^{29}$. Resumiéndolo con un ejemplo predilecto de Dewey: los médicos no tienen una idea de la salud como un fin en sí mismo y absoluto, mediante el cual determinar qué hay que hacer; por el contrario, "crean su idea general de la salud como un fin y un buen valor para sus pacientes apoyándose en que sus técnicas de examen han mostrado cuáles son los problemas que sufre un paciente y cuáles son los medios con los que se superan ${ }^{\prime 30}$.

Como dicen los Putnam, se podría objetar que sin valuings (sin convertir a ciertas cosas en fines genéricos) no puede haber evaluations, y que aquéllas introducen siempre un elemento subjetivo y no racional inelimilable. Dewey niega radicalmente que haya semejante elemento subjetivo o no-racional en las valoraciones; ¿cómo entiende entonces la relación entre valuings y evaluations? En palabras de los Putnam: "Cualquier valoración puede llegar a ser evaluada, aunque no podemos adoptar nunca una posición en la que todas las valoraciones hayan sido evaluadas"31. Según los Putnam, la objeción mencionada sigue exigiendo un fundamento, mientras que para Dewey no hay fundamento: sólo podemos empezar desde la situación donde nos hallamos, que incluye tanto nuestros "sufferings and enjoyments (our valuings)" como nuestras evaluaciones. Nuestros sufrimientos y disfrutes se

28 Ibidem.

29 Ibid., p. 233.

30 Theory of Valuation, Chicago, University of Chicago Press, 1939, p. 46. Véanse los comentarios de $\mathrm{H}$. Thayer sobre estos ejemplos de Dewey en "The Construction of Good" en la IV parte (cap. 3) de su Meaning and Action. A Critical History of Pragmatism, New York, The Bobbs Merril Co. Inc., 1968.

31 "Epistemology as Hypothesis", p. 410. 
convierten en apreciaciones, implican evaluaciones, pero sólo cuando son resultados de nuestras actividades (físicas o intelectuales) ${ }^{32}$. Cuando los Putnam interpretan así las ideas de Dewey, sostienen una tesis que han aclarado en otros contextos: el hecho de que construyamos valores no implica que sean arbitrarios o que unos no puedan ser mejores que otros. Incluso recurren a la comparación entre la creación de valores y la creación de artefactos. Nosotros producimos, literalmente, artefactos, por ejemplo, cuchillos, sin embargo, no los construimos de acuerdo al diseño de la propia naturaleza, ni siempre hay un diseño que se imponga a todos los diseñadores por ley natural. Cuando construimos cuchillos no seguimos el diseño que tiene el propio universo para un cuchillo, pero de ahí no se sigue que los cuchillos no satisfagan necesidades reales. Ciertamente, los cuchillos pueden ser mejores o peores ${ }^{33}$. ¿Pero qué relación hay entre valores y necesidades? Precisamente porque hay necesidades humanas reales, y no sólo deseos, tiene sentido distinguir entre valores mejores y peores. Pero esas necesidades, según Putnam, no están dadas para siempre, sino que a su vez son creadas: la humanidad está constantemente rehaciéndose a sí misma ${ }^{34}$. No hay posibilidad de una fundamentación de la ética más allá de esto, concluye Putnam.

Al insistir en la relación entre valores y resultados de actividades propias, los Putnam también están mostrando lo importante que resulta en la ética de Dewey la suposición de que un enjoyment que nos simplemente viniera sin ningún esfuerzo por nuestra parte --de modo que no pudiera venir como la satisfacción de algún impulso-- no tendría valor. Es cierto que Dewey sugiere en muchas ocasiones que un enjoyment no tiene valor a menos que estimule nuestra curiosidad, a menos que nos empuje a investigar cómo

32 Véase de Ruth Anna Putnam, "Creating Facts and Values", Philosophy, vol 60 , 1985; "Doing what one ought to do", Meaning and Method. Essays in Honour of $H$. Putnam, Boolos, G., (ed.), Cambridge, Cambridge University Press, 1990, pp. 279293.

33 The Many Faces of Realism, p. 78.

34 Ibidem. 
prolongarlo y cómo producirlo de nuevo. En realidad esto podría considerarse como una presuposición característica de la imagen deweyana de la naturaleza humana. De hecho, los Putnam sostienen que Dewey "asume una teoría 'débil' de la naturaleza humana", porque no pretende describir nuestros intereses o derechos qua seres humanos. Su imagen de la naturaleza humana es, por supuesto, revisable en el curso de la experiencia, y su asunción principal es que "lo que los seres humanos valoran, y no sólo valoran, sino que necesitan, no es algún estado pasivo de satisfacción o placer, sino actividad productiva ${ }^{\prime \prime 35}$. Las concepciones humanas del bien son ricas y multifacéticas y sus partes son interdependientes, pero lo que más deseamos es producir lo que concebimos como nuestro bien a través de nuestra propia actividad, y no que nos sea dado. Y, curiosamente, Putnam sugiere explicitamente la proximidad entre Dewey y Aristóteles.

La interpretación de los Putnam deja, por tanto, bastante clara la relación que existe para Dewey entre valuing y evaluation. Dewey no niega que valoremos ciertas cosas (salud, riqueza, justicia, conocimiento); pero lo que a él le interesa de esos bienes es que no los valoramos como algo estático, como fines fijos y determinados de una vez por todas. Bajo la suposición más general de su teoría de la naturaleza humana, lo que más valoramos, y necesitamos, son procesos de crecimiento. Como decia en Reconstruction of Philosophy, es más bien la necesidad de mejorar en asuntos de salud, riqueza, justicia, es más bien ese proceso continuo que va transformando las circunstancias, lo que consideramos como un bien: "la perfección no es una meta final; la meta del vivir es el proceso continuamente madurable de perfeccionamiento, maduración y refinamiento... El crecimiento mismo es el único fin moral ${ }^{136}$. De este modo, "crecimiento" es, por así decirlo, el único fin general compatible con la imagen pragmática que Dewey tiene de la relación entre medios y fines.

"Epistemology as Hypothesis", p. 428. Sub. mío.

La reconstrucción de la filosofía, pp. 240-241. Sub. mío. 
III

Al inicio de la sección anterior comenté que Putnam también ha usado argumentos de Dewey para criticar no sólo el utilitarismo clásico sino también las teorías formales de la decisión. Veamos ahora este asunto. Hemos visto que la tesis de Dewey que más interesa a Putnam es que los juicios de valor tienen lugar en un continuo donde la consecuencia de una acción puede convertirse, a su vez, en medio para obtener otras consecuencias. Como un medio para un fin-en-perspectiva, una situación se puede evaluar tanto en términos de los medios necesarios para su realización como en términos de sus futuras consecuencias. $Y$ todas esas evaluaciones son racionales. No se niega que valoremos ciertas cosas sin consideración de su carácter como medios o consecuencias, pero "aunque esas valoraciones, como las observaciones cualitativas de la vida común, podrían iniciar, y de hecho inician, una indagación, no son, en cualquier caso, su fin" ${ }^{\prime \prime 37}$. Esto supondría para Putnam una negación de la distinción entre hecho y valor, porque desde esta perspectiva los juicios de valor paradigmáticos son tan susceptibles de justificaciones racionales y empíricas como el resto de los juicios: los juicios que describen una situación y que sirven para sugerir posibles fines-a la-vista, son el resultado de procedimientos experimentales y de hábitos de atención gracias a los cuales juzgamos qué características son relevantes, qué informacíon es necesaria y cómo se pueden obtener; $y$, en definitiva, por qué unas situaciones nos parecen problemáticas y otras no en función de los valores que apreciamos.

¿Como se compaginaría este modelo de la deliberación con la psicología que ha estado en la base de algunos presupuestos de la matemática de la economía moderna y de la teoría de la decisión?, pregunta Putnam. En esta teoría, un fin sólo puede ser racionalmente revisado si la indeseabilidad de sus consecuencias se establece por referencia a otro fin (o combinación de fines) que se ordena como más alto que el fin que se revisa. El abandono racional de un 
fin por sus consecuencias siempre requiere que haya un fin (o combinación de fines) de un "rango superior" en la escala de preferencias del agente. En definitiva, la justificación de un fin $A$ por referencia a un fin $B$ y de $B$, a su vez, por referencia a A, es irracional; por tanto, cualquier ordenación de preferencias racionales contiene un fin o combinación de fines que no son susceptibles de crítica racional. Putnam alude a la teoría de von Neumann como una formalización de este modelo que recuperó todo lo que era concluyente en la teoría utilitarista clásica, sin asumir la dudosa psicología en que ésta se basaba. En ella, los jugadores racionales ideales pueden responder a preguntas sobre sus preferencias por "agregados de bienes", combinaciones de cosas tan diferentes como un concierto de música, un lugar para vivir, un amigo, etc... Si las preferencias son perfectamente racionales, entonces es posible asignar utilidades a los fines individuales, de tal manera que se racionalicen todas las apuestas que el jugador está dispuesto a hacer. Y los axiomas de la teoría de von Neumann implican que todas las elecciones pueden ordenarse gradualmente: para cualesquiera dos bienes, $x, y, o$ bien $x$ se prefiere a $y$ (o sea, $x$ e $y$ no son iguales), o bien es indiferente si se obtiene $x$ o y (o sea, $x$ e $y$ son iguales). Todo posible agregado de bienes que uno podría valorar recibe un peso en una serie finita de dimensiones, y la suma de esos pesos es la utilidad global del agregado. Las dimensiones mismas y los pesos que los agregados de bienes reciben en cada una de ellas representan, por así decirlo, fines últimos del orden de preferencia del agente racional.

Según esta representación de la decisión racional, cuando una persona alcanza un fin a la vista y decide que no le gusta o no satisface el agregado de bienes que obtiene, diríamos que las consecuencias de la acción acaecida tienen valores tan bajos en dimensiones distintas a las correspondientes al fin-a-la-vista, que el valor total del agregado de bienes obtenido es inferior al valor de otros agregados que el jugador podría obtener y que no conducen al fin-a-la-vista original. Dicho de otra forma, si consigo un fin y lo evalúo como deventajoso, según esta teoría sólo lo abandono 
porque su valor en relación con otros fines es menor al de otras alternativas posibles que, lógicamente, no conducian a la obtención de ese fin.Pudiera ser que el jugador no sólo decidiera que el coste de la obtención es demasiado alto, sino que decidiera dejar de valorar el fin-a-la-vista original. Pero, entonces, según el modelo, o bien el agente no sabía cuál era realmente su orden de preferencia, o bien habría cambiado su orden de preferencia a causa de un cambio empírico en su naturaleza, algo que por definición no es ni racional ni irracional en este modelo.

Frente a esta representación de la decisión racional, el modelo de Dewey no implica que el abandono racional de un fin requiera la existencia de fines en una escala más alta. Putnam ilustra este punto con el mismo ejemplo que Dewey utilizó para criticar el utilitarismo clásico. Un estudiante empieza la carrera de filosofía, obtiene muy buenos resultados, e incluso sus profesores le consideran un estudiante prometedor. Pero tras una par de años, el estudiante comienza a preguntarse si la filosofía es realmente "lo que quiere hacer". Imaginemos que finalmente opta por una vida de servicio social, en vez de una vida dedicada a la investigación en un departamento de filosofía. Y Putnam pregunta: ¿cuál es el "fin de rango más alto" por el que el estudiante abandona la filosofia? Una respuesta a la que alude Putnam es la de D. Davidson $^{38}$ : según éste, la pregunta por un fin de un orden superior no es en absoluto una pregunta empírica, sino un simple requerimiento a priori de la interpretación de la acción. Dicho de otra forma, al explicar las elecciones de los agentes en términos de una teoría de la acción, debemos adscribirles fines que son de orden superior a los fines originales en cuyos términos una acción pareció al principio deseable. Si la atribución de fines de orden superior implica cierta indeterminación, se debe, simplemente, a

38 Putnam podría estar aludiendo a los comentarios de Davidson sobre la teoría de la decisión en Essays on Actions and Events, Oxford, Clarendon Press, 1980, pp. 229-238. 
que nos encontramos ante un caso particular de la indeterminación de la interpretación.

Pero Dewey rechazó la idea de verdad analítica en filosofía. No negaría que, después de que un agente ha decidido finalmente cambiar su curso de acción, sea correcto decir que esa nueva acción debe haber sido el "fin de orden superior". Tampoco negaria que hablar en estos términos puede ser a veces la explicación correcta de la acción. Lo que negaria es que hablar en esos términos deba ser la explicación correcta. En un caso como el del estudiante de filosofía, donde el agente decide un cambio respecto a una forma de vida, una actividad a largo plazo, un cambio de carácter, lo que importa no es preguntarse cómo conseguir tal o cual fin-a-la-vista, sino, más bien, cómo descubrir el origen de su insatisfacción e instituir un problema. Al estudiante no le interesa la pregunta: ¿cómo alcanzaré ahora tal o cual fin-a-la-vista?, sino: ¿qué fin-a-la-vista perseguiré ahora? Y la formulación del nuevo fin es "ella misma" parte de la resolución de la situación problemática. En cambio, la teoría formal de la acción, comenta Putnam, "confunde la situación describiéndola como si la decisión de abandonar o al menos de interrumpir el estudio de la filosofía, fuera explicada por la conciencia que adquiere el estudiante de un conflicto entre los fines-a-la-vista, mientras que lo que realmente explica la interrupción del estudio de la filosofía, es que el estudiante se encuentra él mismo en una situación problemática -que no puede prolongar--, y el nuevo fin a la vista es la solución provisional a esa situación problemática, no su causa. Este ejemplo ilumina la representación alternativa que da Dewey del cambio racional del valores ${ }^{39}$. La persecución de un fin-a-la-vista para cuya consecución se dispone de medios eficientes puede no sólo conducir a la frustración de otro fin que el agente ya posee, sino a un estado de no-satisfacción (dissatisfaction), y para Dewey concebir la no-satisfacción solamente como la frustración de un fin es, por decirlo con las palabras de Putnam, "la peor clase de psicologiza-

"Epistemology as Hypothesis", pp. 424-425. 
ción a priori". Una forma más adecuada de describir esa clase de no-satisfacción consistiría en decir que la consecución de un fin a la vista conduce a una situación que requiere la construcción de un fin diferente $y$, por tanto, nada es un fin excepto si sirve como medio para guiar la conducta de los agentes o, como diría Dewey: medios y fines forman un continuo, y los fines deberían estar sujetos al mismo control empírico que los medios.

Putnam va incluso más allá de las ideas de Dewey para criticar la teoría formal de la decisión. El concepto clave de esta crítica es la incomparabilidad de algunas opciones. La teoría formal de la decisión sólo contempla la relación de "orden de preferencia" y la de "indiferencia" entre dos opciones dadas. En este modelo, la relación de indiferencia se define a partir de dos axiomas: la transitividad de la preferencia y la transitividad del complemento de la preferencia (esto es, la relación 'no preferir'). En consecuencia, la indiferencia es una relación de equivalencia. Al agente racional le es indiferente elegir entre $x$ e $y$ si no prefiere $x$ a $y$, y no prefiere $y$ a $x$. Pero --insiste Putnam-- la noción formal de indiferencia parece en algunos casos contraintuitiva. En particular, en aquellos casos que Putnam llama "elecciones entre formas de vida alternativas". Según Putnam, estos casos no pueden ser descritos con sólo las relaciones que se siguen de los axiomas de la teoría de la decisión. No pueden ordenarse en una jerarquía porque ni son indiferentes ni sucede que simplemente uno se prefiera al otro.

El teórico de la decisión presenta como simplemente intercambiables dos opciones indiferentes. Por lo tanto, interpreta como no problemática para un jugador racional una situación en la que una instancia externa decide por él cuál de las dos opciones le es ofrecida. Al argumentar, el teórico de la decisión decide en lugar del agente a favor de una de las opciones indiferentes. Dicho de otra forma: el único valor que el teórico de la decisión no puede representarse sólo como un producto más que combina con los agregrados de bienes entre los que ha de escoger, la autonomía. Precisamente, si tengo que elegir entre dos formas de vida alternativas $y$, por lo tanto, me encuentro en proceso de decidir 
qué voy a ser, no puedo dejar de contemplar dichas opciones como elecciones que tengo que hacer por mí mismo. Desde el punto de vista del sentido común, nada puede resultar más irracional que renunciar de antemano a realizar las decisiones existenciales por uno mismo, o mejor dicho, renunciar a la posibilidad de incorporar nuevos fines en el futuro: "¿Podría defender alguien la teoría de la preferencia racional asumiendo que una agente racional ideal ha hecho ya todas sus elecciones existenciales? Haber hecho todas las elecciones existenciales posibles es precisamente haber dejado de crecer, haberse vuelto totalmente rígido como ser humano. No puedo creer que alguien quiera realmente introducir este atributo de algunas personalidades humanas dentro de la 'racionalidad"

\section{IV}

Hasta aquí hemos visto cómo Putnam usa los argumentos de Dewey para criticar tanto el utilitarismo clásico como la teoría formal de la decisión. Antes de acabar, no obstanteo, merece algún comentario la relación que Putnam percibe entre un modelo pragmatista de la racionalidad y el debate en torno al relativismo ético. Según afirma en "A Reconsideration of Deweyan Democracy", Dewey no sólo habría evitado las ilusiones del realismo metafísico "sino también las del relativismo". Para Dewey hay crítica racional de fines, y una vida racionalmente vivida no necesita estar ni guiada ni culminada por un conjunto de fines últimos. Pero entonces, también podría decirse que no hay razón para pensar que los agentes alcanzarán un acuerdo sobre valores, incluso si cada agente por separado lleva lo que podríamos considerar una vida racional. A este respecto, Putnam insiste en que los desacuerdos sobre valores que dan lugar a conflictos son, ellos mismos, experimentados por los agentes y por las comunida-

40 "Rationality in Decision Theory and in Ethics" (Traducción castellana en Racionalidad. Ensayos sobre la racionalidad en ética y política, ciencia y tecnología, Olivé, L., (ed.), México, Siglo XXI, 1988, p. 50). 
des como situaciones problemáticas que requieren una solución, y que la sugerencia de Dewey sería que no tenemos razones para considerar que en discusiones éticas se llegue a problemas más irresolubles de lo que sucede en nuestro conocimiento empírico. En ambos casos, los desacuerdos se pueden solucionar relativizando los juicios en cuestión, y puede ser el caso que sea bueno para unos agentes vivir la vida de una forma y para otros de otra. Como dice Putnam, una situación similar aconteció en la práctica científica cuando se descubrió que los juicios simultáneos de diferentes observadores podrían ser incompatibles. Entonces se resolvió el problema adoptando una teoría de acuerdo con la cual tales juicios son relativos al estado de movimiento del observador. Si los agentes individuales están en desacuerdo sobre sus valores, la resolución del problema no tiene por qué adoptar la forma de principio universal que cada agente pudiera aceptar como válido. Si el desacuerdo atañe a las vidas de cada agente consideradas por separado, entonces el desacuerdo se podría resolver relativizando los juicios en cuestión: "la idea de objetividad ética no es la misma ni presupone la idea de una forma universal de vida. Dewey admite lo primero y, consistentemente, se opone a lo segundo" ${ }^{14}$.

Por supuesto, no todos los conflictos éticos están sujetos a una solución de este tipo; pero cuando esto ocurre, no nos enfrentamos a un problema que exige una solución filosófica universal sino, más bien, a un problema existencial que exige una resolución práctica. Quizá no todos los problemas de este tipo puedan ser resueltos, pero tampoco todos los problemas de la matemática, la física, la geología o la historia, pueden resolverse, "pero eso no da más apoyo a la idea de que la asertabilidad justificada y la verdad existen en un dominio pero no en el otro" ${ }^{\prime 42}$. Considerar la investigación ética como una empresa objetiva no sólo es compatible con la idea de que muchas preguntas sólo tienen respuestas relativas al contexto. También es compatible con mantener que no toda

\footnotetext{
41 "Epistemology as Hypothesis", p. 427.

42

Ibidem.
} 
pregunta tiene una respuesta determinada. Algunas preguntas pueden tener respuestas objetivamente indeterminadas y puede que no se dé una convergencia respecto a esa respuesta, ni siquiera en el sentido en el que pensó Peirce, o sea, ni siquiera en el límite ideal de la investigación ${ }^{43}$. Afirmar que la investigación ética es objetiva equivale a decir que algunos juicios de valor son definitivamente verdaderos $y$ otros falsos, que algunas actitudes $y$ costumbres son definitivamente inocuas y que algunas son definitivamente inferiores a otras. Pero es no es mantener que no existan casos indeterminados ${ }^{44}$. La recomendación deweyana que más le interesa a Putnam es que no podemos juzgar otras formas de vida apelando a la noción estrecha de racionalidad que ha proyectado la cultura moderna. Hay crítica racional de fines de otros (como de los fines propios) sin necesidad de considerar las metas y las preferencias dadas. La adopción y la crítica de los fines de otra forma de vida depende mucho más de la capacidad para imaginar en que consistiría seguir otro fin, y esa capacidad, como dice Putnam, tiene que ver más con la imaginación que con el conocimiento proposicional. La capacidad para comparar formas de vida depende, como hemos visto, de factores como la habilidad para imaginar en qué consistiría un cambio de carácter o una propiedad a largo plazo de la conducta; esto es, depende de la sensibilidad para el significado que un fin tenga para la experiencia considerada.

La distinción entre objetividad y universalidad es, probablemente, la tesis de inspiración deweyana que Putnam más ha desarrollado en el resto de trabajos dedicados a temas éticos. Por ejemplo, lo que ha llamado "imagen moral" en The Many Faces of Realism encaja con su descripción de la tesis pragmatista de la indeterminación en ética. Allí dice que una imagen moral "no es una

43 Putnam analiza los problemas de la noción peirceana de la convergencia en Realism with a Human Face. Véase también "The Importance of Peirce's Puzzle", The Many Faces of Realism, pp. 80-86.

44 Razón, verdad e historia, pp. 150-151. 
declaración de que esto o aquello es una virtud; o que esto o aquello es lo que uno debería hacer; más bien, consiste en una imagen del modo en que nuestras virtudes e ideales encajan entrte sí y una imagen de la relación que deben tener con la posición en que nos encontramos. Podría ser algo tan vago como las nociones de 'hermandad y fraternidad'; de hecho, millones de seres humanos han encontrado en esas metáforas imágenes morales que podrían organizar sus vidas morales pese al enorme problema que representa la interpretación de esas nociones, y decidir que podría significar el volverlos efectivos"45. Como se ve, una imagen moral no es, para Putnam, un simple juicio de valor, ni tampoco una moralidad completa, una lista de virtudes o una descripción de la vida buena, o un conjunto de prescripciones o leyes morales. Una moralidad va más allá de una imagen moral en el sentido de que trata de articular cómo se ha de aplicar esta última. Por eso una imagen moral, o al menos una parte sustancial de ella, puede articularse en un conjunto de enunciados. Gracias a eso se le puede haber crítica racional, "porque una imagen moral podria contradecir, por ejemplo, lo que sabemos o pensamos que es racional creer sobre otras bases, sean lógicas, metafísicas o empíricas" $^{\prime 46}$. Sin embargo, como dice Ruth A. Putnam, deberíamos tomar en serio el uso intencional que Putnam hace del término "imagen": una imagen moral perfila las apreciaciones que hacemos de los hechos tanto como el sentido de relevancia e importancia que adquiere un científico perfila sus apreciaciones de la evidencia. Las imágenes morales son las que nos permiten movernos desde los hechos a conclusiones prescriptivas. Una imagen moral no es un conjunto de creencias, tampoco las virtudes. Tanto unas como otras implican modos de percibir el mundo y pueden ser aprendidas y criticadas, pero lo que se aprende no es un conjunto de "reglas de designación", y la crítica racional "no adopta la forma de refutar una premisa mostrando que

\footnotetext{
45

46

The Many Faces of Realism, p. 51.

Ibid., p. 86.
} 
conduce a conclusiones falsas ${ }^{\prime \prime 4}$. Más bien, las virtudes nos empujan a actuar o somos empujados por nuestras imágenes a concluir que deberiamos actuar de cierta forma $y$, por tanto, --aunque no siempre-- actuamos así. Esas acciones y sus resultados juegan un papel en ética que Dewey siempre comparó con el papel de la experimentación y la observación en ciencia ${ }^{48}$. Hay lugares por los que la red de creencias (sobre hechos y sobre valores) está ligada a la experiencia, y esas experiencias podrían movernos a cambiar no sólo nuestras premisas explícitas sino también nuestra forma entera de pensar, o lo que Putnam llama "imágenes" morales ${ }^{49}$.

En realidad, la noción de Putnam de una imagen moral y su relación con la experiencia también le ha aproximado al William James de Pragmatism, pero sobre todo al James de The Will to Believe. Esto parece seguirse de otros trabajos de Putnam sobre pragmatismo $^{50}$, pero no me extenderé aquí sobre este punto. Lo que me interesaba en este trabajo era justificar la predilección de Putnam hacia la teorí pragmatista de los valores, para justificar

47 R. A. Putnam, "Doing What One Ought to Do" p. 283.

48 Esta comparación entre experimentación en ciencia y ética queda más clara si se tiene en cuenta que para Dewey la práctica científica no se podía reducir al modelo hipotético-deductivo. Como también señalan los Putnam, Dewey destacó especialmente el papel de la experimentación antes de la formulación de una hipótesis (y no sólo después), así como el uso común de hipótesis auxiliares en los pasos deductivos. Dicho con palabras de ellos: "Dewey no reduce los métodos comunes de los científicos ni a los métodos de la lógica deductiva ni a algo tan poco realista como un criterio de falsabilidad.. más bien, insiste en el hecho de que la fase hipotético-deductiva (i.e. inductiva) de la investigación recurre a los resultados de investigación experimental previa" (Epistemology as Hypothesis, p. 413). Esta concepción de la ivestigación está directamnte relacionada con el ataque de Dewey con la distinción entre hecho y valor y, por extensión, con su concepción de las relaciones entre ciencias naturales y ciencias humanas. Véase también a este respecto Putnam, H., Renewing Philosophy, Cambridge, Harvad University Press, 1992, pp. 180 y ss.

49 Véase de R. A. Putnam "Doing what we Ought to do", p. 283. En este punto se apoya en los comentarios de Morton White en "Normative Ethics, Normative Epistemology, and Quine's Holism", L. Hahn \& P. Schlipp (eds.), The Philosophy of V. W. Quine, La Salle, Open Court, 1986, pp. 649-662. 197.

50 Véase Realism with a Humane Face pp. 223-231 y Renewing Philosophy, pp. $192-$ 
una distinción entre objetividad y relativismo ético que ha sido desarrollada en su obra de una forma paralela a la defensa de su realismo interno. Putnam ha mostrado que la falta de fundamentos en ética y en ciencia no nos conduce ni al escepticismo ni al relativismo, y para eso ha sostenido la tesis de que "no podemos decir qué es verdadero o falso idependientemente de algún sistema conceptual, pero dentro de un sistema conceptual dado, las preguntas sobre verdad y falsedad nos atañen. En ética, esto significa que nuestros juicios morales están perfilados por nuestras imágenes morales del mundo y por el propio mundo. No es posible describir el aspecto que tendria el mundo si uno no tuviera ningún punto de vista moral. Esto no significa simplemente que no podemos comprometernos con una reflexión moral si no nos preocupan algunas cosas, si no hay cosas que valorar. Aunque eso también es cierto, significa que cuando nos comprometemos en la reflexión moral no lo hacemos ni con la mentalidad vacía ni con un conjunto de valores eternos o universales. $Y$ esa diferencia es, para Putnam, una diferencia que Dewey señalo cuando contrasto valuing y evaluation, o entre prizing y appraising". ${ }^{51}$ Esta estrecha similutud entre la actitud de Putnam hacia nociones epistémicas y éticas podría explicar el que ya hablara en Razón, verdad e historia de Dewey como un "relativista objetivo". Para un relativista de este estilo los valores no son relativos en el sentido de ser meras cuestiones de opinión; es decir, no se socava la racionalidad de los juicios de valor, sino que se intenta explicar la convicción del sentido común de que algunos valores son objetivamente relativos, --es decir, que son racionales dadas las circunstancias, la naturaleza y la historia de los que los crean. Para Putnam, como para Dewey, lo que muestra a tientas el relativismo tradicional es que lo que es correcto o falso es relativo a las circunstancias, pero eso no implica que no no exista ni la correción ni la incorreción, ni siquiera en las circunstancias que se especifiquen. De la inexistencia de valores (en el sentido deweyano de esa tesis) no se sigue

51 Ruth A. Putnam, "Doing what one ought to do", p. 288. 
que cualquier cosa sea exactamente tan buena como cualquier otra, sino que no existe la relación "ser exactamente tan bueno como".

En realidad, Putnam podría contraponer el relativismo y el realismo metafísico al pragmatismo, porque, para él, el error principal de estas perspectivas es que "no se corresponden en absoluto con la forma que tenemos de pensar y en la que seguiremos pensando". En cierta ocasión, recuerda Putnam, Davidson le planteó la siguiente pregunta retórica: "¿Qué objeto tiene decir que el leguaje intencional es de 'segunda clase' si vamos a seguir usándolo?". La pregunta --dice Putnam--es una buena pregunta pragmatista porque "el corazón del pragmatismo fue la inistencia en la supremacía del punto de vista del agente. Si encontramos que debemos adoptar cierto punto de vista o sistema conceptual cuando nos vemos implicados en la acción práctica (en el sentido más amplio de actividad práctica), entonces no debemos sostener al mismo tiempo que, realmente, las cosas no son así 'en sí mismas'"152. El modelo pragmatista del valor podría, por tanto, entenderse como la versión ética de la tesis de Putnam de que podemos superar el realtivismo y el realismo metafísico sin negar las intuiciones realistas del sentido común.

La relación entre la obra reciente de Putnam y el legado de la filosofía norteamericana es, como dije al inicio de este trabajo, mucho más compleja de lo que ha parecido. Aquí he esbozado un conjunto de polémicas sobre las que Putnam tiene aún muchas más cosas que decir. Sin duda, la publicación de su nuevo libro Pragmatism: An Open Question, anunciada para inicios del próximo año, nos deparará un material imprescindible para seguir discutiendo su "imagen" de la racionalidad. 